\title{
Resiliency as a Mediator in the Relationship Between Aggressiveness and School Achievement - Differences Related to Gender and Levels of Physical Activity
}

\author{
Magdalena Jochimek \\ Gdansk University of Physical Education and Sport \\ Ariadna Łada-Maśko \\ University of Gdańsk \\ Mariusz Lipowski ( $\square$ mariusz.lipowski@awf.gda.pl) \\ Gdansk University of Physical Education and Sport
}

\author{
Research Article \\ Keywords: school achievement, aggressiveness, resiliency, physical activity, adolescence \\ Posted Date: November 24th, 2020 \\ DOI: https://doi.org/10.21203/rs.3.rs-107008/v1 \\ License: (1) This work is licensed under a Creative Commons Attribution 4.0 International License. Read Full License
}




\section{Abstract}

\section{Background}

Taking part in physical activity has a major positive influence on the development of adolescents. Research shows that physical activity has an impact on cognitive and behavioral functioning. Aggressiveness is a factor negatively correlated with school achievement and resiliency is a protective factor for coping with stressful situations. The purpose of this study is to analyze the mediation effect of resiliency as a dispositional protective factor in the relationship between aggressiveness and school achievement in the context of gender and levels of physical activity.

Methods

The research was carried out on $N=787$ adolescents $\left(M_{\text {age }}=15.95 ; S D=.29\right)$ from the Pomeranian region in Poland. The participants were divided into three subgroups: 1) a non-active group, $n=130$ (90 girls); 2) a Physical Education (PE) group, $n=490$ (303 girls); and 3) an athlete group, $n=130$ (65 girls). The following research tools were used in the study: a socio-demographic survey; a questionnaire about average grades at the end of the school year; the Adolescent Aggressiveness Questionnaire - Emotional Reactivity; and the Resiliency Assessment Scale for Children and Adolescents to evaluate resiliency levels.

Results

Analyzing the average school grades, resiliency, as well as levels of aggressiveness and its components revealed statistically significant differences in terms of gender and physical activity. Furthermore, the effects of general aggressiveness level and all its components on average school grade, mediated by resiliency, proved insignificant for boys in all three research groups and for girls in the athlete group. However, the analysis showed a mediation effect of resiliency in relation to emotional irritability and average school grade in the group of non-active girls. The mediation analysis revealed significant mediation effects for emotional irritability, opposition, and verbal aggression, as well as for general aggressiveness levels in the group of PE girls.

Conclusions

Resiliency is a protective factor in the relation between aggressiveness and school achievement, especially in the female PE group. The mechanisms governing boys' functioning seem different and require further research. Compulsory physical education classes may help build resources that facilitate learning.

\section{Background}

A positive school climate translates into building relationships and creating an atmosphere that facilitates learning [3]. Research indicates that if students perceive a school as an institution which fosters the development of their relationships with their peers as well as teacherstudent relationships, their emotional well-being is boosted and peer violence is considerably diminished [4]. According to International Health Behaviour in School-aged Children (HBSC) research, there has been a decrease in aggressive behaviors (operationalized as taking part in bullying classmates [5]), but this remains one of the most urgent problems in schools [6]. Research shows that the most common aggressive behavior at school is verbal teasing and that girls are more indirect, while boys usually use physical bullying [7]. Aggressive behavior is a significant risk factor that increases the likelihood of teenagers adopting rule-breaking behaviors [8], which are associated with lower school achievement [9] and even failure to graduate [10]. Moreover, socially maladjusted behavior such as disobedience and aggressiveness, which are considered externalized symptoms according to Achenbach [11], are strong negative predictors of academic achievement and this effect is higher for girls compared to boys [12]. Generally, in different stages of education, females have better grades at school than males [13], despite having the same global intellectual ability levels [14]. Therefore, the mediating role of personality traits is worth considering in the influence of gender on school achievement. An example of this kind of mediator is disconstraint [15]. Moreover, Kristensson and Öhlund [16] identified a strong negative association between school grades and aggression, but there is also a strong positive relationship between school grades and sense of coherence and coping resources, which are stress protective mediators.

One potential mediator between aggressiveness and school achievement could be resiliency. In this context, resiliency is understood as a personal resource which is relatively constant in time [2], which appears even in very difficult situations, such as a stay at an orphanage [17]. Resiliency is described as a meta-resource because this personality disposition is considered to be a self-regulation mechanism [18] that consists of cognitive elements as well as emotional and behavioral components [19-22]. In line with research by Block and Kremen [19], the resilient personality type is the opposite of both the undercontrolled (impulsive) and overcontrolled (rigid) types. It is important to highlight in this respect that resiliency is linked to flexible adaptation to a situation as well as being able to cope with difficult emotions and that this 
influences academic success [23] and is positively associated with study progress [24]. Moreover, resiliency is a more important predictor of academic performance than gender [25]. Research shows the resilient personality type is related to higher school achievement and that children with undercontrolled personalities are more aggressive in adolescence than those with resilient or overcontrolled personalities [26]. Moreover, if a teacher classifies a student as aggressive, the student's level of resiliency will affect their school achievement [27].

It should be added that psychological competencies associated with sports foster the development of resiliency and athletes are characterized by higher levels of this personality trait [28, 29]. Participation in obligatory physical education classes at school may develop self-regulation and the ability to control aggressive behaviors [30], which is in accordance with the assumptions of the Physical Education Core Curriculum used in schools in Poland. It's worth mentioning that a meta-analysis conducted by Spruit et al. [31] revealed significant small-to-moderate effects of physical activity interventions on externalizing problems and school achievement. Undoubtedly, the healthier a pupil is, the greater their school achievement will be [32], and physical activity is one of the pillars of health [33].

Furthermore, physical activity has a positive influence on cognitive functioning [34, 35] and students' school achievement [36]. Adolescents' participation in organized sports activities may positively affect educational outcomes [37]. In contrast, the more time children spend on sedentary forms of leisure time activities (e.g., video games, TV, Internet), the higher their levels of aggression, which is why sport should be promoted as an active form of spending time [38]. To summarize, research shows that participating in sports positively affects school achievement, but this relationship is mediated by psychosocial problems [39]. Moreover, there is still a need for research into the effects of physical activity (type, frequency, duration, intensity) on school achievement [40].

Accordingly, the purpose of this study is to analyze the mediation effect of resiliency as a dispositional protective factor in the relation between aggressiveness and school achievement in the context of gender and levels of physical activity. Therefore, we created three research questions:

1. Does the gender and level of physical activity of teenagers differentiate their levels of resiliency, aggression, and school grades?

2. Does resiliency mediate the relationship between levels of aggression and school grades, depending on gender and levels of physical activity?

\section{Methods}

\subsection{Participants}

The participants in the study were 787 adolescents $\left(M_{\text {age }}=15.95 ; S D=.29\right)$ from Pomerania in Poland. They were purposively selected from teenagers characterized by different levels of physical activity. We excluded $4.26 \%$ of adolescents from the analysis as they did not report their average academic performance.

Participants were divided into three subgroups, based on their results on the The Inventory of Physical Activity Objectives [41]: 1) a nonactive group, $n=130$ (90 girls) - adolescents who are exempt from physical education classes and did not declare taking part in any physical activity in their free time; 2 ) a physical education class group (PE), $n=490$ (303 girls) - adolescents who only do physical activity during school hours; and 3) an athlete group, $n=167$ (79 girls) - adolescents who train regularly (average declared hours spent training each week: $M=14.07 ; S D=5.16$ ), have valid club licences, and represent clubs in at least country-level competitions. The athlete group included individuals who train team sports (soccer, basketball, handball, volleyball), individual sports (such as sport gymnastics, track-andfield, or swimming), aesthetic disciplines (artistic gymnastics, dance), as well as martial arts (judo, fencing).

\subsection{Procedure}

Before starting, the project was approved by the Ethics Committee for research projects blinded for review. The sample was selected using purposive random sampling. Schools were selected for the study at random (10 of 12 sport schools and 25 of 381 general education schools) from the Pomeranian Office of Education database. Of all the students who were invited to take part in the study, we ultimately obtained complete data from only $65 \%$ of students from general schools and $55 \%$ from sports schools. Written consent to participate in the study was collected from all students and their parents, and they were informed that they could withdraw from participation in the study at any time.

\subsection{Measures}


We used The Inventory of Physical Activity Objectives (IPAO) by Lipowski and Zaleski [41] to determine the level of teenagers' involvement in physical activity, The Resiliency Measurement Scale (SPP-18) by Ogińska-Bulik and Juczyński [2] was used to assess the resiliency personality trait and The Adolescent Aggressiveness Questionnaire - Emotional Reactivity (KAM-RE) by Sajewicz-Radtke et al. [1] was used to examine aggressiveness in adolescents. School achievement was taken as the average grade obtained on the basis of grades from all school subjects in the last school year. A sociodemographic questionnaire was also used.

\subsubsection{The Inventory of Physical Activity Objectives (IPAO; Lipowski and Zaleski [41])}

Only the part of the inventory that allows the analysis of engagement in physical activity was used. Questions concerned involvement in competitive sports and the forms and intensities of physical activity (number of hours devoted to sports, regular participation in physical education classes, physical activity in free time - organized or unorganized).

\subsubsection{Resiliency in children and adolescents (SPP-18; Ogińska-Bulik and Juczyński [2])}

The Resiliency in Children and Adolescents Scale by Ogińska-Bulik and Juczyński [2] measures resiliency as a relatively stable feature of one's personality that fosters the process of positive adaptation. The authors decided against adapting one of the English versions of the test to Polish conditions, as there is a lack of clear preference among researchers regarding the available methods for measuring resiliency. The tool was constructed such that it allows the measurement of resiliency in the context of the process of efficient coping with traumatic events as well as everyday stress. SPP-18 allows for the measurement of the levels of mental resiliency (a relatively stable trait) as well as for the detailed description of a teenager's functioning in terms of four dimensions of resiliency: 1) "Optimistic Life Attitude and Energy", 2) "Determination and Persistence in Action", 3) "Sense of Humor and Openness to New Experiences", and 4) "Personal Competence and Tolerance of Negative Affect". The internal consistency of SPP-18 assessed using Cronbach's a is 0.82 .

Respondents have to assess up to 18 items on a five-point Likert scale ( 0 - strongly disagree, 1 - somewhat disagree, 2 - neither agree nor disagree, 3 - somewhat agree, 4 - strongly agree). The total points indicates the respondent's level of resiliency (the higher the total, the higher the resiliency). Moreover, it is possible to transform the raw scores into a sten scale (where 1-4 indicates low, 5-6 average, and 7-10 high resiliency).

\subsubsection{The Adolescent Aggressiveness Questionnaire - Emotional Reactivity (KAM-RE; Sajewicz-Radtke et al. [1])}

The Adolescent Aggressiveness Questionnaire - Emotional Reactivity (KAM-RE) [1] was used to measure levels of aggressiveness. It consists of 60 items, on which the respondent indicates the extent to which a statement describes their behavior on a five-point Likert scale ( 1 - not at all, 2 - very little, 3 - I don't know, 4 - somewhat, 5 - to a great extent). The questionnaire contains 5 subscales:

1. Direct aggression - the tendency to use physical force to cause harm when the other person is trying to avoid it.

2. Indirect aggression - behaviors connected with harming other people in ways such as bursts of anger, malicious jokes, stamping one's legs, or gossip; physical violence is excluded.

3. Emotional irritability - the tendency to show negative emotions at even the slightest provocation from other people.

4. Opposition - behaviors which undermine authority, including fighting against and opposing rules as well as social norms or customs.

5. Verbal aggression - expressing difficult emotions both in terms of verbal content and tone (e.g., swearing or shouting).

The result of the questionnaire is the total of the points scored on each statement (the higher the score, the higher the level of aggressiveness). It is also possible to calculate the level of aggression for each of the subscales. The test-retest reliabilities for the test subscales were $0.80-0.87$ and for the overall score was .90 [1]. Cronbach's a values in this study for the subscales were: .86 for direct aggression, .73 for emotional irritability, .86 for indirect aggression, .79 for opposition, and .85 for verbal aggression. For the general aggression level, Cronbach's a was .94.

\section{Results}

Table 1 presents descriptive statistics and Pearson's $r$ correlations between the variables in the model. General aggressiveness level and, particularly, direct aggression, indirect aggression, opposition, and verbal aggression were negatively correlated with average school grade. A significant positive correlation was found between average school grade and resiliency. Moreover, the analyses indicated that general 
aggressiveness level and most of its components (indirect aggression, emotional irritability, opposition, and verbal aggression) were negatively correlated with resiliency. No statistically significant correlations were found between average school grade and emotional irritability or between direct aggression and resiliency.

Table 1 Descriptive statistics and correlations between average school grade, aggressiveness, and resiliency

\begin{tabular}{|c|c|c|c|c|c|c|c|c|c|}
\hline & & 1. & 2. & 3. & 4. & 5. & 6. & 7. & 8. \\
\hline 1. & Average school grade & 1 & $-.27 \star \star$ & $-.21 \star \star$ & -.04 & $-.19 \star \star$ & $-.10 \star \star$ & $-.20 \star \star$ & $.17 * \star$ \\
\hline 2. & Direct aggression & $-.27^{\star \star}$ & 1 & $.77^{\star \star}$ & $.35^{\star \star}$ & $.61^{\star \star}$ & $.54 \star \star$ & $.81^{\star \star}$ & -.04 \\
\hline 3. & Indirect aggression & $-.21^{\star \star}$ & $.77 \star \star$ & 1 & $.45^{\star \star}$ & $.70 \star \star$ & $.60 * \star$ & $.88^{\star \star}$ & $-.13^{\star *}$ \\
\hline 4. & Emotional irritability & -.04 & $.35^{\star \star}$ & $.45^{\star \star}$ & 1 & $.56^{\star \star}$ & $.65^{\star \star}$ & $.70 * \star$ & $-.21^{\star \star}$ \\
\hline 5. & Opposition & $-.19 \star \star$ & $.61 * \star$ & $.70 \star \star$ & $.56^{\star \star}$ & 1 & $.69 \star \star$ & $.85^{\star \star}$ & $-.11^{\star \star}$ \\
\hline 6. & Verbal aggression & $-.10^{\star \star}$ & $.54 * \star$ & $.60 \star \star$ & $.65^{\star \star}$ & $.69 \star *$ & 1 & $.85^{\star \star}$ & $-.13^{\star *}$ \\
\hline 7. & Aggressiveness & $-.20 \star \star$ & $.81 * \star$ & $.88^{\star \star}$ & $.70 \star \star$ & $.85^{\star \star}$ & $.85^{\star \star}$ & 1 & $-.15^{\star \star}$ \\
\hline 8. & Resiliency & $.17 \star \star$ & -.03 & $-.13^{\star \star}$ & $-.21^{\star \star}$ & $-.11^{\star \star}$ & $-.13^{\star \star *}$ & $-.15^{\star \star}$ & 1 \\
\hline & $M$ & 4.19 & 20.81 & 29.97 & 26.86 & 21.48 & 34.93 & 134.06 & 48.45 \\
\hline & $S D$ & .76 & 7.30 & 9.30 & 5.88 & 5.83 & 8.82 & 30.70 & 11.24 \\
\hline
\end{tabular}

$* p<.05, * * p<.001$

Using analysis of variance [42] with post hoc Tukey analysis, differences between girls and boys who are non-active, those who only do physical activity in school, and athletes in terms of average school grades, aggressiveness levels and the components thereof, and resiliency were examined. To evaluate the above differences with regard to gender and sport, a two-way ANOVA (2: gender $\times 3$ : sport) was performed (Table 2).

Table 2 Differences in average school grade, resilience, and aggressiveness with respect to gender and physical activity [42]

\begin{tabular}{|c|c|c|c|c|c|c|c|c|c|}
\hline & $\begin{array}{l}\text { Female } \\
\text { non- } \\
\text { active } \\
(n= \\
90)\end{array}$ & $\begin{array}{l}\text { Female } \\
\text { PE } \\
(n=303)\end{array}$ & $\begin{array}{l}\text { Female } \\
\text { athletes } \\
(n=79)\end{array}$ & $\begin{array}{l}\text { Male } \\
\text { non- } \\
\text { active } \\
(n= \\
40)\end{array}$ & $\begin{array}{l}\text { Male } \\
\text { PE } \\
(n=187)\end{array}$ & $\begin{array}{l}\text { Male } \\
\text { athletes } \\
(n=88)\end{array}$ & Gender & PA & $\begin{array}{l}\text { Gender } x \\
\text { PA }\end{array}$ \\
\hline & $M(S D)$ & $M(S D)$ & $M(S D)$ & $M(S D)$ & $M(S D)$ & $M(S D)$ & $F\left(p^{*}\right)$ & $F\left(p^{*}\right)$ & $F\left(p^{*}\right)$ \\
\hline $\begin{array}{l}\text { Average school } \\
\text { grade }\end{array}$ & $\begin{array}{l}3.82 \\
(.73)\end{array}$ & $4.34(.67)$ & $4.32(.62)$ & $\begin{array}{l}3.54 \\
(.92)\end{array}$ & $3.96(.79)$ & $\begin{array}{l}3.94 \\
(.68)\end{array}$ & $\begin{array}{l}30.36(< \\
.001)\end{array}$ & $\begin{array}{l}19.83(< \\
.001)\end{array}$ & $.27(.767)$ \\
\hline Resiliency & $\begin{array}{l}45.16 \\
(12.57)\end{array}$ & $47.30(11.05)$ & $\begin{array}{l}52.04 \\
(12.65)\end{array}$ & $\begin{array}{l}48.53 \\
(10.24)\end{array}$ & $\begin{array}{l}47,49 \\
(9.43)\end{array}$ & $\begin{array}{l}54.55 \\
(10.44)\end{array}$ & $\begin{array}{l}4.47 \\
(.035)\end{array}$ & $\begin{array}{l}19.53 \\
(<.001)\end{array}$ & $\begin{array}{l}1.34 \\
(.264)\end{array}$ \\
\hline $\begin{array}{l}\text { Direct } \\
\text { aggression }\end{array}$ & $\begin{array}{l}21.44 \\
(7.22)\end{array}$ & $18.54(6.84)$ & $\begin{array}{l}20.04 \\
(7.17)\end{array}$ & $\begin{array}{l}24.83 \\
(7.12)\end{array}$ & $22.45(6.68)$ & $\begin{array}{l}23.37 \\
(7.92)\end{array}$ & $\begin{array}{l}33.31 \\
(<.001)\end{array}$ & $6.93(.001)$ & $.14(.873)$ \\
\hline $\begin{array}{l}\text { Indirect } \\
\text { aggression }\end{array}$ & $\begin{array}{l}32.12 \\
(8.88)\end{array}$ & $27.97(9.36)$ & $\begin{array}{l}29.80 \\
(9.21)\end{array}$ & $\begin{array}{l}34.45 \\
(9.16)\end{array}$ & $\begin{array}{l}30.50 \\
(8.16)\end{array}$ & $\begin{array}{l}31.66 \\
(10.43)\end{array}$ & $\begin{array}{l}7.86 \\
(.005)\end{array}$ & $9.18(<.001)$ & $.08(.922)$ \\
\hline $\begin{array}{l}\text { Emotional } \\
\text { irritability }\end{array}$ & $\begin{array}{l}28.78 \\
(6.17)\end{array}$ & $27.91(6.03)$ & $\begin{array}{l}27.93 \\
(6.13)\end{array}$ & $\begin{array}{l}25.85 \\
(5.55)\end{array}$ & $\begin{array}{l}25.16 \\
(5.00)\end{array}$ & $\begin{array}{l}25.23 \\
(5.15)\end{array}$ & $\begin{array}{l}24.70 \\
(<.001)\end{array}$ & $1.44(.238)$ & $.49(.613)$ \\
\hline Opposition & $\begin{array}{l}23.48 \\
(6.07)\end{array}$ & $20.55(6.13)$ & $\begin{array}{l}21.20 \\
(5.92)\end{array}$ & $\begin{array}{l}23.53 \\
(5.09)\end{array}$ & $\begin{array}{l}21.42 \\
(5.22)\end{array}$ & $\begin{array}{l}22.09 \\
(5.32)\end{array}$ & $\begin{array}{l}1.43 \\
(.232)\end{array}$ & $\begin{array}{l}8.58 \\
(<.001)\end{array}$ & $.24(.784)$ \\
\hline $\begin{array}{l}\text { Verbal } \\
\text { aggression }\end{array}$ & $\begin{array}{l}38.53 \\
(9.09)\end{array}$ & $34.39(9.46)$ & $\begin{array}{l}34.80 \\
(8.88)\end{array}$ & $\begin{array}{l}35.48 \\
(7.63)\end{array}$ & $\begin{array}{l}34.33 \\
(7.60)\end{array}$ & $\begin{array}{l}34.23 \\
(8.44)\end{array}$ & $\begin{array}{l}2.59 \\
(.108)\end{array}$ & $4.19(.016)$ & $1.31(.270)$ \\
\hline Aggressiveness & $\begin{array}{l}144.36 \\
(30.47)\end{array}$ & 129.37(31.67) & $\begin{array}{l}132.86 \\
(31.29)\end{array}$ & $\begin{array}{l}144.12 \\
(29.23)\end{array}$ & $\begin{array}{l}133.86 \\
(26.72)\end{array}$ & $\begin{array}{l}136.58 \\
(32.47)\end{array}$ & $1.01(.316)$ & $\begin{array}{l}7.76 \\
(<.001)\end{array}$ & $.27(.763)$ \\
\hline
\end{tabular}


Statistically significant differences in terms of both gender and physical activity were observed in average school grades, resiliency, direct aggression, and indirect aggression. Girls had higher average school grades than boys (Cohen's $d=.46$ ); adolescents who did not participate in any physical activity classes had lower average school grades than the PE and athlete groups, which did not differ from each other $\left(\eta^{2}=.05\right)$. In contrast, boys scored significantly higher than girls for resiliency (Cohen's $d=.17$ ), direct aggression (Cohen's $d=.52$ ), and indirect aggression (Cohen's $d=.24$ ). Furthermore, post hoc Tukey analysis indicated that the athlete group scored significantly higher on resiliency $\left(\eta^{2}=.05\right)$ than the other two groups (non-active and PE), which did not significantly differ from each other. For both direct $\left(\eta^{2}=\right.$ .02 ) and indirect aggression $\left(\eta^{2}=.03\right)$, the PE group scored significantly lower than the other groups. There were also differences depending on gender in emotional irritability, where girls scored significantly higher than boys (Cohen's $d=.47$ ), while physical-activity-related differences were observed for opposition, verbal aggression, and general level of aggressiveness. For opposition, the PE group scored lowest $\left(\eta^{2}=.03\right)$, while the other two did not differ significantly from each other; the non-active group presented significantly higher levels of verbal aggression $\left(\eta^{2}=.02\right)$ and general levels of aggressiveness $\left(\eta^{2}=.03\right)$ than the PE and athlete groups. No gender $\times$ PE effects were observed for the measured variables.

Next, to answer the research question about whether the impact of aggressiveness level on average school grade is mediated by resiliency and whether this depends on the participants gender and level of physical activity, mediation analyses were performed for the three research groups described above for girls and boys, both together and separately. Firstly, in order to determine the sample size for a mediation analysis, we conducted a power analysis using $G *$ Power $[43,44]$. It showed that the number of participants was sufficient to achieve a large effect size (f2) of .35, with an alpha of .05 and a power level of .95. Subsequently, using the PROCESS bootstrapping macro [45], general aggressiveness level and its components (direct aggression, indirect aggression, emotional irritability, opposition, and verbal aggression) were entered as predictors, resilience as the hypothesized mediator, and average school grade as the dependent variable (we applied Model 4 from the PROCESS bootstrapping macro).

We found that the effects of general aggressiveness level and all its components on average school grade, mediated by the resiliency, were insignificant for boys in all three research groups. However, some mediation effects of resiliency were found for girls in the relation between general aggressiveness level and its components on average school grade in the female non-active and PE groups.

\subsection{Resiliency as a mediator between aggressiveness and average school grade in the non-active female group}

The effect of emotional irritability on average school grade was fully mediated by resiliency; the bootstrap confidence interval for the indirect effect $(b=-0.01)$ based on 5000 bootstrap samples (see Figure 1 ) was entirely below zero: [-0.017, -0.001$]$. Thus, we found no direct effect of emotional irritability on average school grade $(b=-0.01, S E=.13, t=-1.16, p=.251,95 \% \mathrm{Cl}$ for $b=[-0.040,0.011])$. However, direct effects of emotional irritability on resiliency $(b=-0.52, S E=.21, t=-2.47, p=.016,95 \% \mathrm{Cl}$ for $b=[-0.936,-0.101])$, as well as resiliency on average school grade $(b=0.01, S E=.01, t=2.24, p=.027,95 \% \mathrm{Cl}$ for $b=[.002, .026])$ were found. $\mathrm{R}^{2}$ for the model $=.09 ; F(2,87)=4.11, p=$ .019 .

\subsection{Resiliency as a mediator between aggressiveness and average school grade in the female PE group}

The mediation analysis showed significant mediation effects for three components of aggressiveness (emotional irritability, opposition, and verbal aggression) and also for general aggressiveness level in the female PE group. The effect of emotional irritability on the average school grade in the female PE group was fully mediated by resiliency (see Figure 2); the bootstrap confidence interval for the indirect effect $(b=-0.01)$ based on 5000 bootstrap samples was entirely below zero: $[-0.010,-0.001]$.

Thus, we found no direct effect of emotional irritability on the average school grade $(b=-0.01, S E=.01, t=-1.28, p=.203,95 \% \mathrm{Cl}$ for $b=$ $[-0.022,0.005])$. However, direct effects of emotional irritability on resiliency $(b=-0.56, S E=.10, t=-5.62, p<.001,95 \% \mathrm{Cl}$ for $b=[-0.762$, $-0.367])$, as well as resiliency on the average school grade $(b=0.01, S E=.01, t=2.40, p=.017,95 \% \mathrm{Cl}$ for $b=[.002, .005])$ were found. $\mathrm{R}^{2}$ for the model $=.04 ; F(2,300)=5.13, p=.007$. 
The results also indicate that the effect of opposition on average school grade was partly mediated by resiliency; the bootstrap confidence interval for the indirect effect $(b=-0.02)$ based on 5000 bootstrap samples (see Figure 3 ) was entirely below zero: $[-0.008,-0.002]$.

Moreover, direct effects of opposition on resiliency $(b=-0.39, S E=.10, t=-3.80, p<.001,95 \% \mathrm{Cl}$ for $b=[-0.586,-0.186])$ and resiliency on average school grade $(b=0.01, S E=.01, t=2.42, p=.016,95 \% \mathrm{Cl}$ for $b=[0.002,0.15])$ were found. A direct effect of opposition on average school grade $(b=-0.01, S E=.01, t=2.15, p=.033,95 \% \mathrm{Cl}$ for $b=[-0.026,-0.001])$ was also found. $\mathrm{R}^{2}$ for the model $=.04 ; F(2,300)=6.66 ; p$ $=.002$.

The effect of verbal aggression on average school grade was partly mediated by resiliency; the bootstrap confidence interval for the indirect effect $(b=-0.01)$ based on 5000 bootstrap samples (see Figure 4) was entirely below zero: $[-0.005,-0.001]$.

Thus, we found no direct effect of verbal aggression on average school grade $(b=-0.01, S E=.01, t=-1.82, p=.070,95 \% \mathrm{Cl}$ for $b=[-0.016$, $0.001])$. However, direct effects of verbal aggression on resiliency $(b=-0.33, S E=.07, t=-3.40, p<.001,95 \% \mathrm{Cl}$ for $b=[-0.355,-0.094])$, as well as resiliency on average school grade $(b=0.01, S E=.01, \mathrm{t}=2.54, p=.012,95 \% \mathrm{Cl}$ for $b=[0.002,0.016])$ were found. $\mathrm{R}^{2}$ for the model $=$ $.04 ; F(2,300)=5.99, p=.003$.

The analysis also confirmed the partial mediation of resiliency in the relation between general aggressiveness and average school grade; the bootstrap confidence interval for the indirect effect $(b=-0.01)$ based on 5000 bootstrap samples (see Figure 5$)$ was entirely below zero: $[-0.002,-0.001]$.

We also found a direct effect of verbal aggression on average school grade $(b=-0.01, S E=.01, t=-2.60, p=.010,95 \% \mathrm{Cl}$ for $\mathrm{b}=[-0.006$, $-0.001])$. Furthermore, direct effects of verbal aggression on resiliency $(b=-0.08, S E=.02, t=-.4 .04, p<.001,95 \% \mathrm{Cl}$ for $b=[-0.118,-0.041])$ as well as resiliency on average school grade $(b=0.01, S E=.01, t=2.30, p=.022,95 \% \mathrm{Cl}$ for $b=[0.001,0.015])$ were found. $\mathrm{R}^{2}$ for the model $=.05 ; F(2,300)=7.76, p<.001$.

\section{Discussion}

\subsection{Levels of resiliency, aggressiveness, and average school grades - gender and physical activity level differences}

Our results suggest that there was no interaction between gender and levels of physical activity in terms of differences in resiliency, aggressiveness, or average school grades. However, gender differences and differences associated with levels of physical activity were observed in the studied variables.

It is interesting that boys scored higher on resiliency. This is in contrast to previous results found by the creators of the resiliency scale [2], as well as in research on older adolescents [29]. It is worth mentioning that the group of respondents who scored highest on resiliency consisted of people engaging in sports. As suggested by Bell \& Suggs [46] and Bell [28], traits that constitute resiliency can be developed, and sports activity is associated with a need for elastic adaptation to novel stressors (both during training sessions and competition). Moreover, athletes characterized by higher resiliency have more positive perceptions of difficult situations and are more likely to use taskfocused stress coping styles [47]. Thus, it seems valid to state that thanks to their participation in sports, both teenage and adult athletes are characterized by higher levels of resiliency $[29,48,49]$, which is in line our results.

In line with expectations, boys scored significantly higher than girls on direct aggression, which corresponds with the results of other authors $[50,51]$. It is not surprising that girls scored higher than boys in terms of emotional irritability, meaning that if they read a situation as being a provocation or failure, they are more prone to react with anger and negative emotions. Research by Caprara et al. [52] suggests that this dimension of aggression is higher and more stable over time in girls, while in boys it decreases with age. It is surprising that boys scored higher than girls on the indirect aggression scale, which is not in line with other research $[7,50]$. This discrepancy could be explained by referring to the results of a metaanalysis conducted by Card et al. [51], which showed that boys score higher on indirect aggression in self-report studies, while girls score higher in studies using objective assessments (from teachers and parents). 
Our results show that school-based physical education classes play an important role in preventing aggressive behavior. Teenagers who regularly engage in physical activity scored lower on direct and indirect aggression, opposition, verbal aggression, and general level of aggressiveness. It should be emphasized that the non-active group presented significantly higher levels of verbal aggression and general levels of aggressiveness than did the PE and athlete groups. Physical education in schools plays a role in not only educating youths about pro-health lifestyles, but it also encourages the socio-emotional development of students, in terms of their social skills, social behaviors, and pro-school attitudes [53]. It is worth mentioning that the higher one's levels of physical activity, the better one's emotion regulation [54]; thus, the basic levels of physical activity provided by physical education classes may constitute a kind of a minimum, encouraging the processes associated with emotion regulation. As previously mentioned in the Introduction, participation in physical education classes at school may be a factor encouraging the development of self-regulation skills and the ability to control aggressive behaviours [30].

Our results, like those of other authors $[13,55]$ show that females get higher average school grades than males. For this reason, it is important to study the factors which contribute to this gender difference. Research conducted in Germany indicates that girls get better grades in German language classes, but the differences diminish in the case of mathematics [56]. Gender differences in terms of results in German language classes are the result of differences in behavior regulation, a skill at which girls are more competent. On the other hand, behavior regulation was not observed to be a mediator of the relationship between gender and mathematics grades, though there was a significant indirect effect of behavior regulation in the relationship between gender and mathematics grades.

It is worth noting that adolescents who did not participate in any physical activity classes had lower average school grades than the PE athlete groups. This is in line with previous research on the relationship between physical inactivity and academic achievement. Physically inactive teenagers in South Korea have below-average academic records [57]. Research by Ardila and Gómez-Restrepo [58] also shows that physical inactivity predicts lower grades, though these analyses pertained to a specific ethnic minority group of students in higher education. Other results also suggest that physical activity is positively related to academic performance $[59,60]$. As indicated by our research, participation in school-based physical education classes seems to be the minimal level of physical activity positively associated with the average grades obtained by teenagers. This is an important result in the context of a metaanalysis conducted by Rasberry et al. [61], who showed that physical activity and academic performance are either positively correlated or there is no relationship between them, as well as the Active Smarter Kids study, which showed that physical activity is a predictor of academic performance [62].

\subsection{Resiliency as a mediator in the relationship between aggressiveness and school achievement - differences related to gender and the level of physical activity}

First, it should be noted that the effects of levels of general aggressiveness and all its components on average school grade, mediated by the resiliency, were insignificant for boys in all three research groups. These results suggest that different protective factors are at play for boys and girls and also that specific differences in the functioning of boys and girls exist. This is in line with other research [63], which shows that in the case of youth at risk of delinquency, both girls and boys who are characterized by higher resilience to this phenomenon are also characterized by significantly higher amounts of various resources. However, in the case of girls, this resistance is to a greater extent associated with more positive school environments. Moreover, models which assume that protective factors (protective-protective model) have a cumulative impact on aggression were significant only for females, which may be related to gender differences in developmental factors and socialization [64]. For this reason, gender differences may also occur in school achievement, and our research suggests that resiliency is a protective factor preventing general aggressiveness and its components from influencing average school grades in non-active girls and those who take PE classes.

It remains puzzling that despite the higher levels of resiliency among athletes, this personality variable did not turn out to mediate the relationship between the dimensions of aggressiveness and mean school grades. It should be emphasized that young athletes face both the demands associated with participating in sports (training sessions, sport camps, competitions), while at the same time performing the duties associated with fulfilling the requirements of their school program. They often approach their large volume of responsibilities in one of the following three ways: a balance between sport and education, the domination of sports over education, or dissonance between sports and education [65]. Moreover, in line with the research by Bradley and Conway [66], the transfer of benefits from practicing sports to school achievement is possible through building non-cognitive skills during physical education classes that take place at school. A strong sense of belongingness and competition with others fosters the development of motivation, openness-to-experience, conscientiousness, and also increased self-efficacy. Thus, in our study, resilience could have not played the role of mediator between the dimensions of aggressiveness and school achievement in individuals who practice sports. 
Interestingly, participation in PE classes at school is a significant factor fostering the protective effect of resiliency on the relationship between aggressiveness and school achievement. The results of our study suggest that emotional irritability, opposition, verbal aggression, and general aggressiveness negatively affected average school grades in the female PE group, and resiliency is a significant protective factor in this case. Thus, it is possible to infer that, for girls, participating in obligatory PE classes at school fosters the development of skills which together constitute resiliency, such as optimistic life attitude and energy, determination and persistence in action, sense of humor, openness to new experiences, personal competence, and tolerance of negative affect [2] as well as their transfer to school achievement. It is worth stressing that merely participating in PE classes does not ensure that the teenagers fulfill the recommendations for pro-health physical activity [67]. For this reason, promoting engaging in physical activity before, during, and after school is a relevant and important topic in many countries [68].

\section{Limitations}

Undoubtedly, future research regarding school achievement in the context of personality dispositions and engagement in physical activity should tightly control the type of sport and whether or not it is practiced in a school club (additional training sessions organized at school) or a club outside of school. The transfer of resources built when practising sports to school grades might differ between the two cases (practicing sports at school might be more beneficial). Moreover, the studied groups of teenage athletes and teenagers who were not physically active were significantly smaller than the group of teenagers who participated in school physical education classes. In the future, methods should be introduced to also make it possible to objectively measure vigorous physical activity. Another important aspect of future research will be to expand the research model to include risk factors and protective factors associated with both the school and family environments which might influence teenagers' grades.

\section{Conclusions}

Resiliency is a protective factor in the relationship between aggressiveness and school achievement, especially in the female PE group, even though there was no discrepancy between the female non-active and PE groups in terms of this personality trait. Thus, compulsory physical education classes may make it possible to accumulate resources which facilitate learning through the acquisition of tension release skills, which, in turn, facilitate concentration during classes as well as tolerance of failure. The mechanisms governing functioning in boys seem different and require further research. Grades achieved by boys were lower than those achieved by girls and the physically inactive group achieved lower grades than the physically active groups.

\section{Declarations}

\section{Ethics approval and consent to participate}

The study is in accordance with guidelines and regulations of the Helsinki Declaration. The project was approved by the Ethics Board for Research Projects at the Institute of Psychology, University of Gdansk, Poland (decision no. 4/2014). Written consent to participate in the study was collected from all students and their parents, and they were informed that they could withdraw from participation in the study at any time.

\section{Consent for publication}

Not applicable.

\section{Availability of data and materials}

The datasets used and/or analysed during the current study are available from the corresponding author on reasonable request.

\section{Competing interests}

The authors declare that they have no competing interests.

\section{Authors' contributions}

$M J$ and $M L$ contributed to conception and design of the study. MJ was managing the project. $M L$ and $M J$ were collecting the data. MJ and $A t-M$ organized the database. At-M and ML performed the statistical analysis. MJ and $A t-M$ wrote the first draft of the manuscript. $M L, M J$ and $\mathrm{A} \mathrm{L}-\mathrm{M}$ were responsible for the manuscript review and editing. All authors read and approved the final manuscript. 


\section{References}

1. Sajewicz-Radtke U, Radtke BM, Kalka D: Kwestionariusz Agresywności Młodzieży - Reaktywność Emocjonalna (KAM-RE)[The Adolescent Aggressiveness Questionnaire - Emotional Reactivity (KAM-RE)]. Gdańsk: Pracownia Testów Psychologicznych i Pedagogicznych 2010.

2. Ogińska-Bulik N, Juczyński Z: Prężność u dzieci i młodzieży charakterystyka i pomiar - Polska skala SPP 18 [Resiliency in children and adolescents: Characteristic and measurement - Polish scale SPP-18]. Forum Psychol. 2011, 16(1).

3. Dulay S, Karadağ E: The Effect of School Climate on Student Achievement. In: The Factors Effecting Student Achievement. Edited by Karadağ E: Springer; 2017: 199-213.

4. Alcantara SC, González-Carrasco M, Montserrat C, Viñas F, Casas F, Abreu DP: Peer violence in the School Environment and Its Relationship with Subjective Well-Being and Perceived Social Support Among Children and Adolescents in Northeastern Brazil. Happiness Stud. 2017, 18(5):1507-1532.

5. Heinz A, van Duin C, Kern MR, Catunda C, Willems H: Trends from 2006-2018 in Health, Health Behaviour, Health Outcomes and Social Context of Adolescents in Luxembourg. In.: University of Luxembourg; 2020.

6. Gaspar S, Guedes FB, Cerqueira A, Oliveira R, Matos M: Physical fights involvement in school setting and adolescents' behaviours: highlights from health behaviour in school-aged children (HBSC/WHO)-fights in school setting and adolescent's behaviours. Care Epidemiol. Glob. Health 2019:1-7.

7. Markkanen I, Välimaa R, Kannas L: Forms of Bullying and Associations Between School Perceptions and Being Bullied Among Finnish Secondary School Students Aged 13 and 15. J. Bullying Prev. 2019:1-10.

8. Ehrenreich SE, Beron KJ, Underwood MK: Social and physical aggression trajectories from childhood through late adolescence: Predictors of psychosocial maladjustment at age 18. Psychol. 2016, 52(3):457-462.

9. Savage J, Ferguson CJ, Flores L: The effect of academic achievement on aggression and violent behavior: A meta-analysis. Violent Beh. 2017, 37:91-101.

10. Dishion TJ: Cross-setting consistency in early adolescent psychopathology: Deviant friendships and problem behavior sequelae. Pers. 2000, 68(6):1109-1126.

11. Achenbach TM: The Child Behavior Profile: An Empirically Based System for Assessing Children's Behavioral Problems and Competencies. J. Men. Health 1978, 7(3-4):24-42.

12. Aluja A, Blanch A: Depressive mood and social maladjustment: Differential effects on academic achievement. J. Psychol. Educ. - EJPE (Instituto Superior de Psicologia Aplicada) 2004, 19(2):121-131.

13. Voyer D, Voyer S: Gender Differences in Scholastic Achievement: A Meta-Analysis. Bull. 2014, 140(4):1174-1204.

14. Steinmayr R, Spinath B: Sex differences in school achievement: what are the roles of personality and achievement motivation? J. Pers. 2008, 22(3):185-209.

15. Carvalho RGG: Gender differences in academic achievement: The mediating role of personality. Individ. Differ. 2016, 94:54-58.

16. Kristensson P, Öhlund LS: Swedish upper secondary school pupils' sense of coherence, coping resources and aggressiveness in relation to educational track and performance. J. Caring Sci. 2005, 19(1):77-84.

17. Ogińska-Bulik N, Kobylarczyk M: Resiliency and social support as factors promoting the process of resilience in adolescents - wards of children's homes. Health Psychol. Rep. 2015, 3(3):210-219.

18. Ogińska-Bulik N, Juczyński Z: Osobowość: stres a zdrowie [Personality: stress and health]. Warsaw: Difin; 2010.

19. Block J, Kremen AM: IQ and ego-resiliency: Conceptual and empirical connections and separateness. Pers. Soc. Psychol. 1996, 70(2):349-361.

20. Block J: Personality as an affect-processing system: Toward an integrative theory. New Jersey: Erlbaum; 2002.

21. Block J, Block JH: The role of ego-control and ego-resiliency in the organization of behavior. In: Development of cognition, affect, and social relations: The Minnesota symposia on child psychology Vol 13. Edited by Collins A. New Jersey: Erlbaum; 1980: 49-112.

22. Letzring TD, Block J, Funder DC: Ego-control and ego-resiliency: Generalization of self-report scales based on personality descriptions from acquaintances, clinicians, and the self. Res. Pers. 2005, 39(4):395-422.

23. Alessandri G, Zuffianò A, Eisenberg N, Pastorelli C: The role of ego-resiliency as mediator of the longitudinal relationship between family socio-economic status and school grades. Youth Adolesc. 2017, 46(10):2157-2168.

24. Backmann J, Weiss M, Schippers MC, Hoegl M: Personality factors, student resiliency, and the moderating role of achievement values in study progress. Individ. Differ. 2019, 72:39-48. 
25. Ayyash-Abdo H, Sanchez-Ruiz M-J, Barbari ML: Resiliency predicts academic performance of Lebanese adolescents over demographic variables and hope. Individ. Differ. 2016, 48:9-16.

26. Hart D, Hofmann V, Edelstein W, Keller M: The relation of childhood personality types to adolescent behavior and development: A longitudinal study of Icelandic children. Psychol. 1997, 33(2):195-205.

27. Morrison GM, Robertson L, Harding M: Resilience factors that support the classroom functioning of acting out and aggressive students. Sch. 1998, 35(3):217-227.

28. Bell CC: Cultivating resiliency in youth. Adolesc. Health 2001, 29(5):375-381.

29. Lipowski M, Lipowska M, Jochimek M, Krokosz D: Resiliency as a factor protecting youths from risky behaviour: Moderating effects of gender and sport. J. Sport Sci. 2016, 16(2):246-255.

30. Costin SE, Jones DC: Friendship as a facilitator of emotional responsiveness and prosocial interventions among young children. Psychol. 1992, 28(5):941-947.

31. Spruit A, Assink M, van Vugt E, van der Put C, Stams GJ: The effects of physical activity interventions on psychosocial outcomes in adolescents: A meta-analytic review. Psychol. Rev. 2016, 45:56-71.

32. Basch CE: Physical activity and the achievement gap among urban minority youth. Sch. Health 2011, 81(10):626-634.

33. Janssen I, LeBlanc AG: Systematic review of the health benefits of physical activity and fitness in school-aged children and youth. J.Behav. Nutr.Phys. Act. 2010, 7(1):40.

34. Bidzan-Bluma I, Lipowska M: Physical activity and cognitive functioning of children: a systematic review. J. Environ. Res. Public Health 2018, 15(4):800.

35. Stroth S, Hille K, Spitzer M, Reinhardt R: Aerobic endurance exercise benefits memory and affect in young adults. Rehabil. 2009, 19(2):223-243.

36. Howie EK, Pate RR: Physical activity and academic achievement in children: A historical perspective. Sport Health Sci. 2012, 1(3):160169.

37. Bird KS, Tripney J, Newman M: The educational impacts of young people's participation in organised sport: a systematic review. Child. Serv. 2013, 8(4):264-275.

38. Kozina A: Aggression in primary schools: the predictive power of the school and home environment. Stud. 2014, 41(1):109-121.

39. Busch V, Loyen A, Lodder M, Schrijvers AJP, van Yperen TA, de Leeuw JRJ: The Effects of Adolescent Health-Related Behavior on Academic Performance: A Systematic Review of the Longitudinal Evidence. Educ. Res. 2014, 84(2):245-274.

40. Castelli DM, Centeio EE, Hwang J, Barcelona JM, Glowacki EM, Calvert HG, Nicksic HM: VII. The history of physical activity and academic performance research: informing the future. Soc. Res. Child Dev. 2014, 79(4):119-148.

41. Lipowski M, Zaleski Z: Inventory of Physical Activity Objectives - a new method of measuring motives for physical activity and sport. Health Psychol. Rep. 2015, 3(1):47-58.

42. Casanova GM, Domanic J, McCanne TR, Milner JS: Physiological responses to child stimuli in mothers with and without a childhood history of physical abuse. Child Abuse Negl. 1994, 18(12):995-1004.

43. Faul F, Erdfelder E, Buchner A, Lang A-G. G*Power Version 3.1.2 [computer software]. Germany: Uiversität Kiel; 2007. Available from: http://www.psycho.uni-535 duesseldorf.de/abteilungen/aap/gpower3/download-and-.

44. Faul F, Erdfelder E, Buchner A, Lang A-G: Statistical power analyses using G*Power 3.1: Tests for correlation and regression analyses. Res. Methods 2009, 41(4):1149-1160.

45. Hayes AF: Introduction to Mediation, Moderation, and Conditional Process Analysis: A Regression-Based Approach. New York, NY: The Guilford Press; 2013.

46. Bell CC, Suggs, H. : Using sports to strengthen resiliency in children. Training heart. Child Adolesc. Psychiatr. Clinic. N. Am. 1998, 7(4):859-865.

47. Litwic-Kaminska K, Izdebski P: Resiliency against stress among athletes. Health Psychol. Rep. 2016, 4(1):79-90.

48. Cevada T, Cerqueira LS, Moraes HSd, Santos TMd, Pompeu FAMS, Deslandes AC: Relação entre esporte, resiliência, qualidade de vida e ansiedade. Clin. Psychiatr. (São Paulo) 2012, 39:85-89.

49. Deuster PA, Silverman MN: Physical fitness: a pathway to health and resilience. US Army Med. Dep. J. 2013:24-35.

50. Björkqvist K: Gender differences in aggression. Opin. Psychol. 2018, 19:39-42.

51. Card NA, Stucky BD, Sawalani GM, Little TD: Direct and Indirect Aggression During Childhood and Adolescence: A Meta-Analytic Review of Gender Differences, Intercorrelations, and Relations to Maladjustment. Child Dev. 2008, 79(5):1185-1229. 
52. Caprara GV, Paciello M, Gerbino M, Cugini C: Individual differences conducive to aggression and violence: trajectories and correlates of irritability and hostile rumination through adolescence. Behav. 2007, 33(4):359-374.

53. Bailey R: Physical education and sport in schools: a review of benefits and outcomes. Sch. Health 2006, 76(8):397-401.

54. Isasi CR, Ostrovsky NW, Wills TA: The association of emotion regulation with lifestyle behaviors in inner-city adolescents. Behav. 2013, 14(4):518-521.

55. Duckworth AL, Seligman ME: Self-discipline gives girls the edge: Gender in self-discipline, grades, and achievement test scores. Educ. Psychol. 2006, 98(1):198-208.

56. Weis M, Heikamp T, Trommsdorff G: Gender differences in school achievement: The role of self-regulation. Psychol. 2013, 4(442).

57. Shin Y-S, So W-Y: Association between Physical Inactivity and Academic Record in Korean Adolescents. J. Public Health 2012, 41(10):36-42.

58. Ardila CM, Gómez-Restrepo ÁM: Frequency of physical inactivity and insufficient sleep, and their mixed effects on academic achievement in ethnic minority students: A matched case-control study in a dental school. Educ. Health Promot. 2020, 9:138-138.

59. Singh A, Uijtdewilligen L, Twisk JWR, van Mechelen W, Chinapaw MJM: Physical Activity and Performance at School: A Systematic Review of the Literature Including a Methodological Quality Assessment. Pediatr. Adolesc. Med. 2012, 166(1):49-55.

60. Terence D, James FS, Leigh B, Ross L, Kimberlie D: Relation of Academic Performance to Physical Activity and Fitness in Children. Exerc. Sci. 2001, 13(3):225-237.

61. Rasberry CN, Lee SM, Robin L, Laris BA, Russell LA, Coyle KK, Nihiser AJ: The association between school-based physical activity, including physical education, and academic performance: A systematic review of the literature. Med. 2011, 52:S10-S20.

62. Aadland KN, Ommundsen Y, Aadland E, Brønnick KS, Lervåg A, Resaland GK, Moe VF: Executive Functions Do Not Mediate Prospective Relations between Indices of Physical Activity and Academic Performance: The Active Smarter Kids (ASK) Study. Psychol. 2017, 8(1088).

63. Hartman JL, Turner MG, Daigle LE, Exum ML, Cullen FT: Exploring the Gender Differences in Protective Factors: Implications for Understanding Resiliency. J. Offender Ther. Comp. Criminol. 2008, 53(3):249-277.

64. Hollister-Wagner GH, Foshee VA, Jackson C: Adolescent aggression: Models of resiliency. Appl. Soc. Psychol. 2001, 31(3):445-466.

65. Ryba TV, Stambulova NB, Selänne H, Aunola K, Nurmi J-E: "Sport has always been first for me" but "all my free time is spent doing homework": Dual career styles in late adolescence. Sport Exerc. 2017, 33:131-140.

66. Bradley JL, Conway PF: A dual step transfer model: Sport and non-sport extracurricular activities and the enhancement of academic achievement. Educ. Res. J. 2016, 42(4):703-728.

67. WHO: Global recommendations on physical activity for health: World Health Organization; 2010.

68. McMullen J, Ni Chróinín D, Tammelin T, Pogorzelska M, van der Mars H: International Approaches to Whole-of-School Physical Activity Promotion. Quest 2015, 67(4):384-99.

\section{Figures}




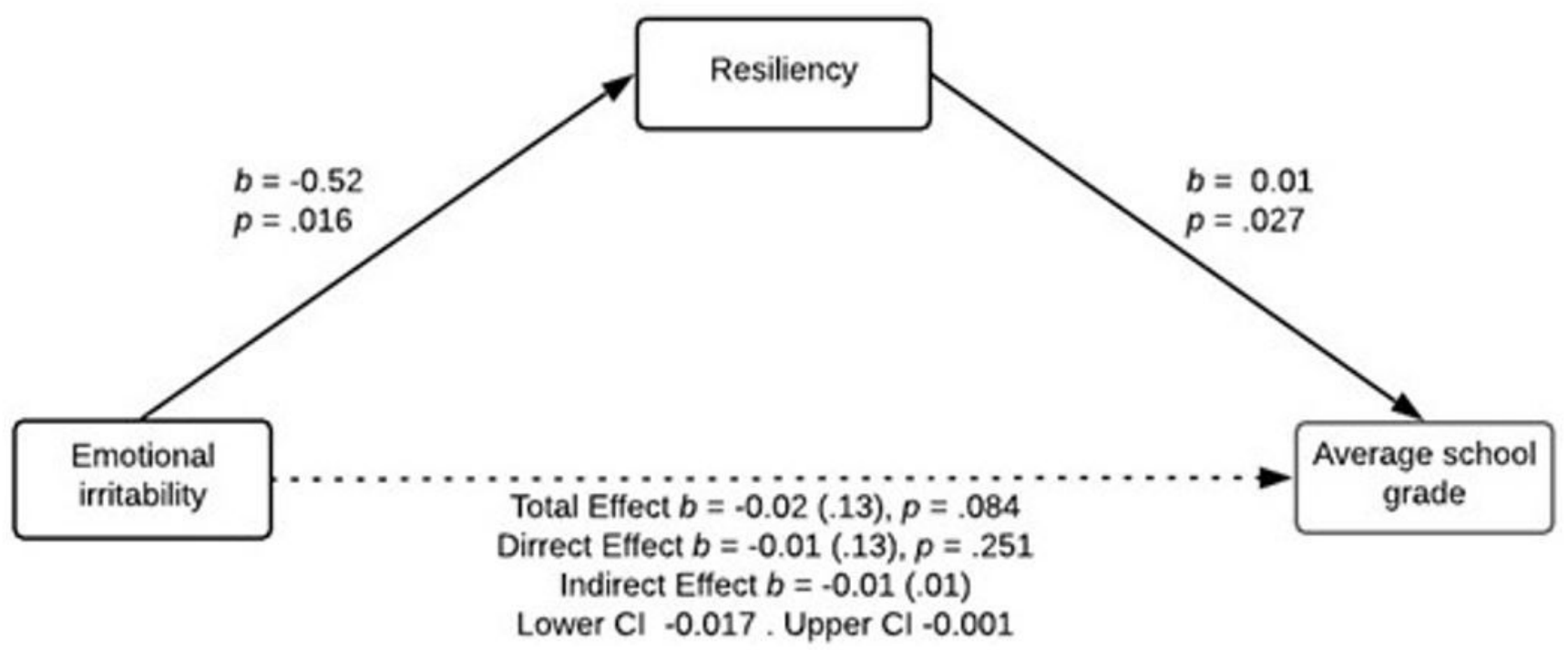

Figure 1

The relationship between emotional irritability and average school grade mediated by resiliency in the non-active female group. Note. Standard errors are provided in parentheses.

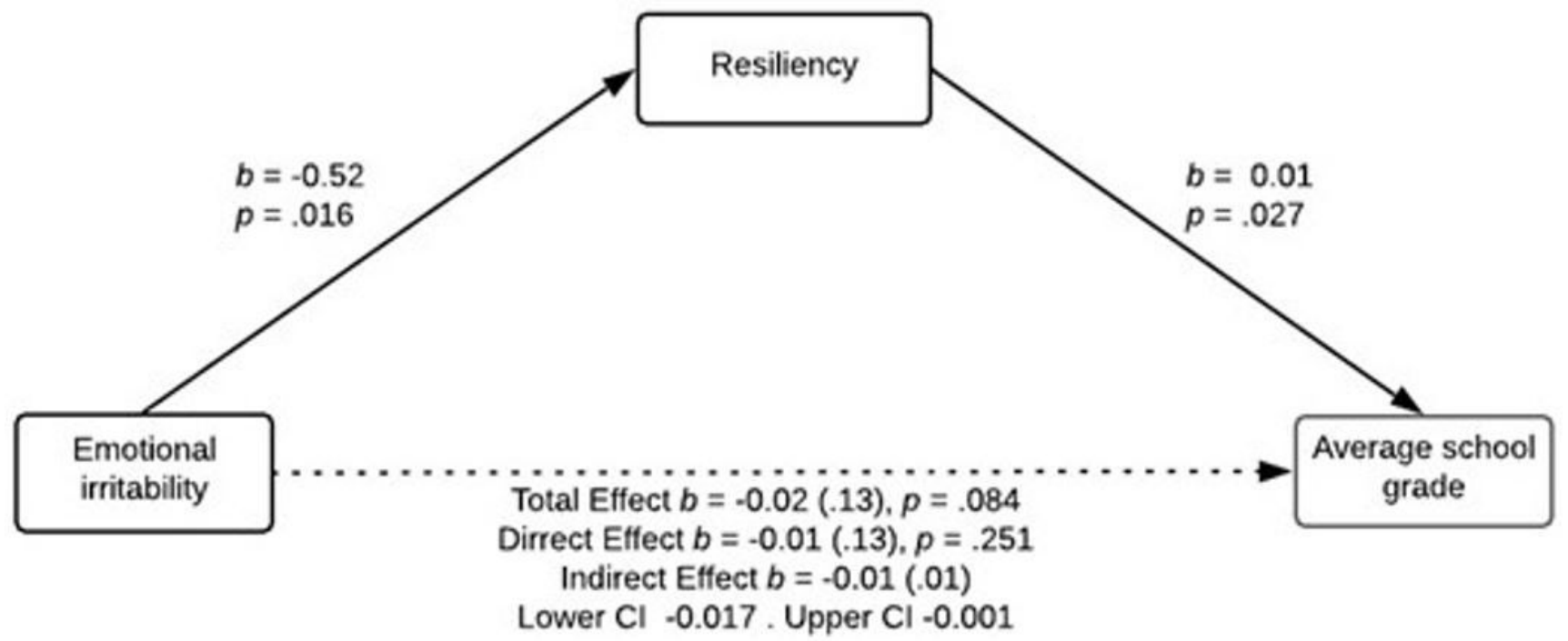

Figure 1

The relationship between emotional irritability and average school grade mediated by resiliency in the non-active female group. Note. Standard errors are provided in parentheses. 


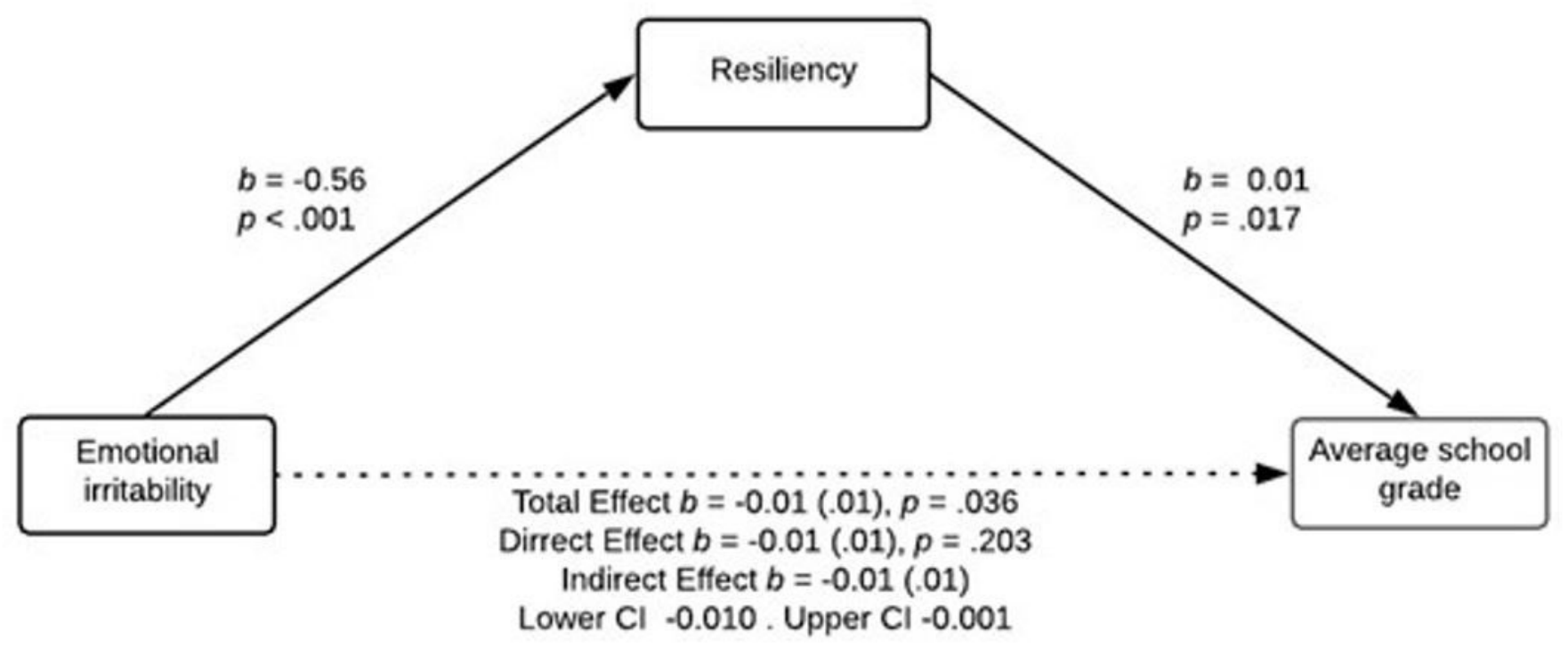

Figure 2

The relationship between emotional irritability and average school grade mediated by resiliency in the female PE group. Note. Standard errors are provided in parentheses.

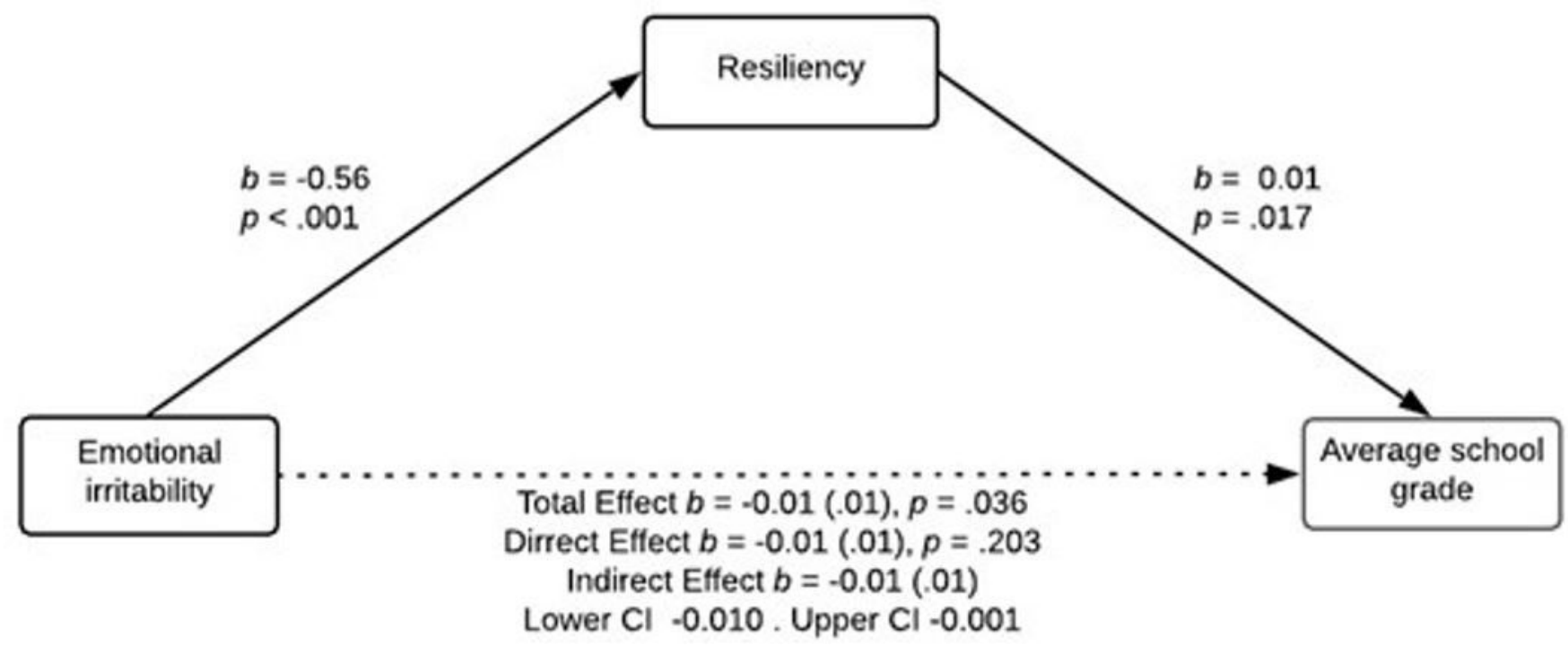

\section{Figure 2}

The relationship between emotional irritability and average school grade mediated by resiliency in the female PE group. Note. Standard errors are provided in parentheses. 


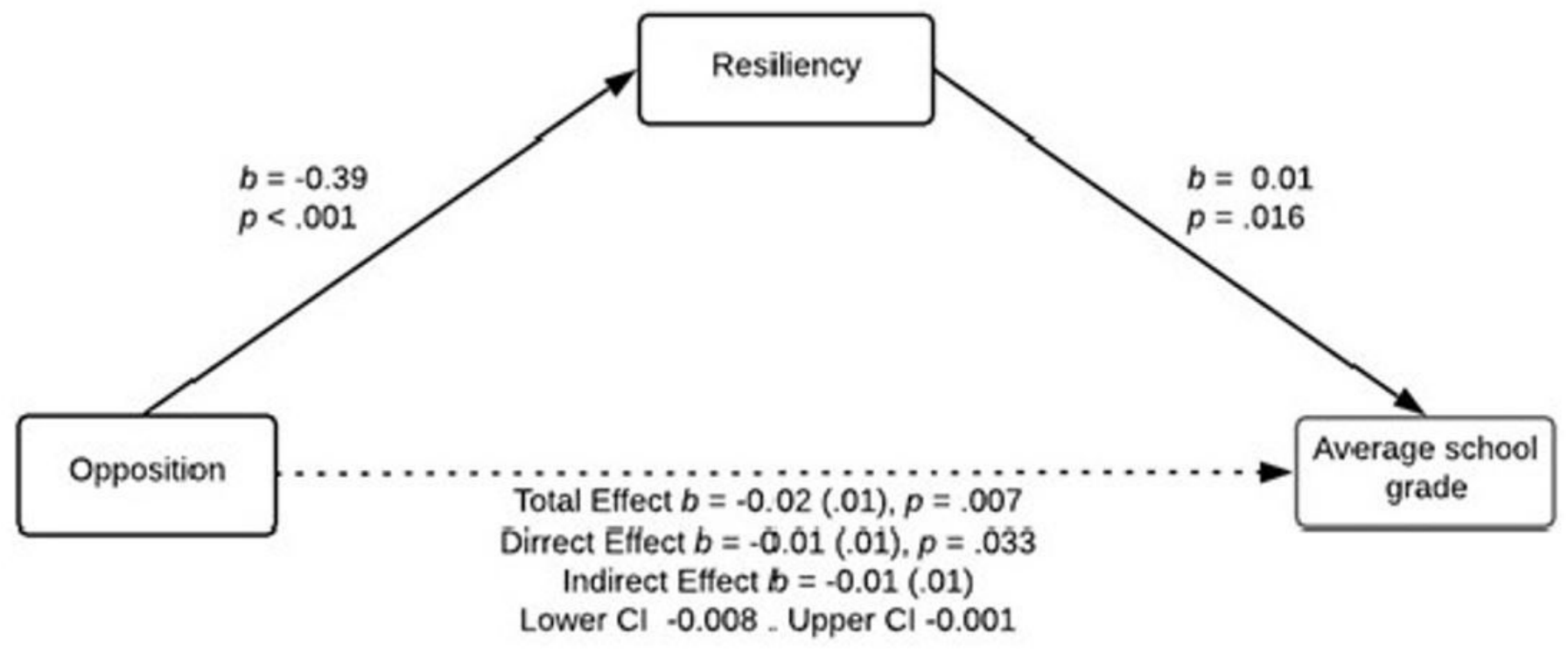

Figure 3

The relationship between opposition and average school grade mediated by resiliency in the female PE group. Note. Standard errors are provided in parentheses.

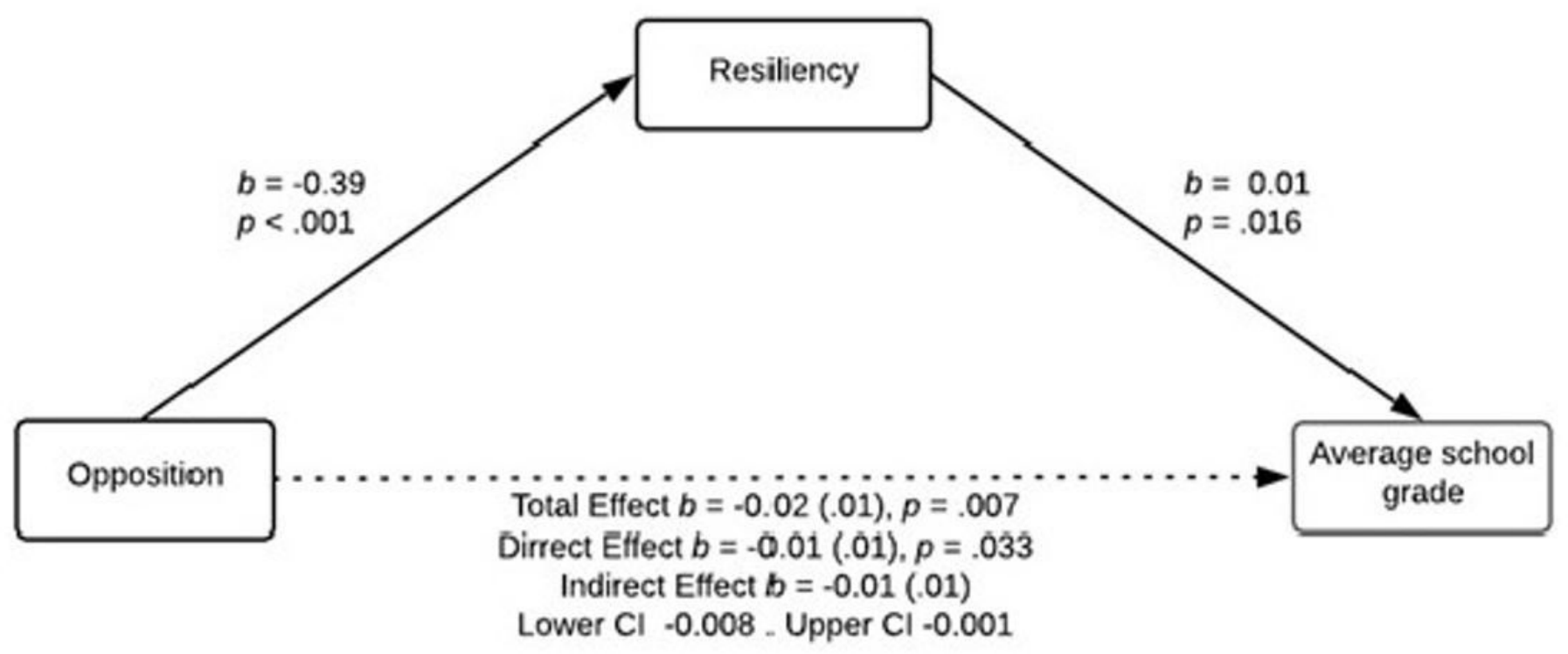

Figure 3

The relationship between opposition and average school grade mediated by resiliency in the female PE group. Note. Standard errors are provided in parentheses. 


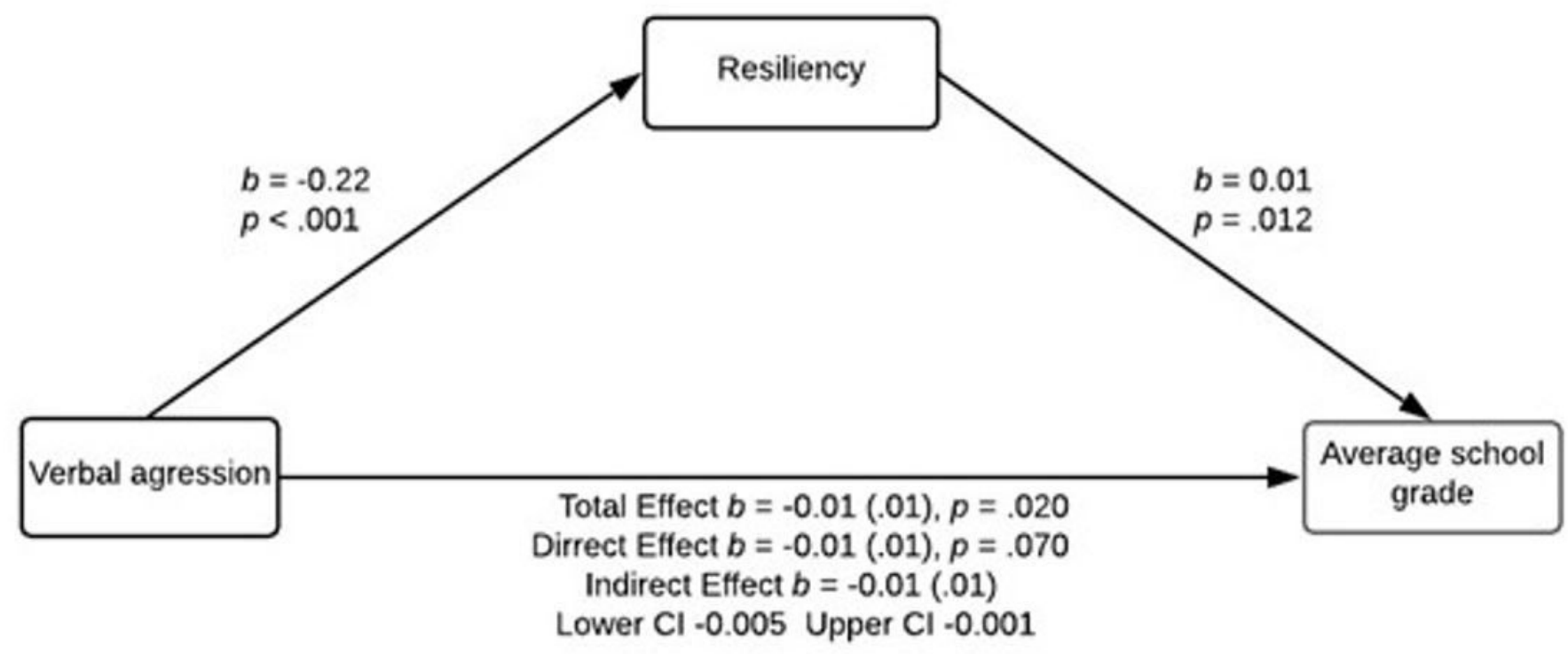

Figure 4

The relationship between verbal aggression and average school grade mediated by resiliency in the female PE group. Note. Standard errors are provided in parentheses.

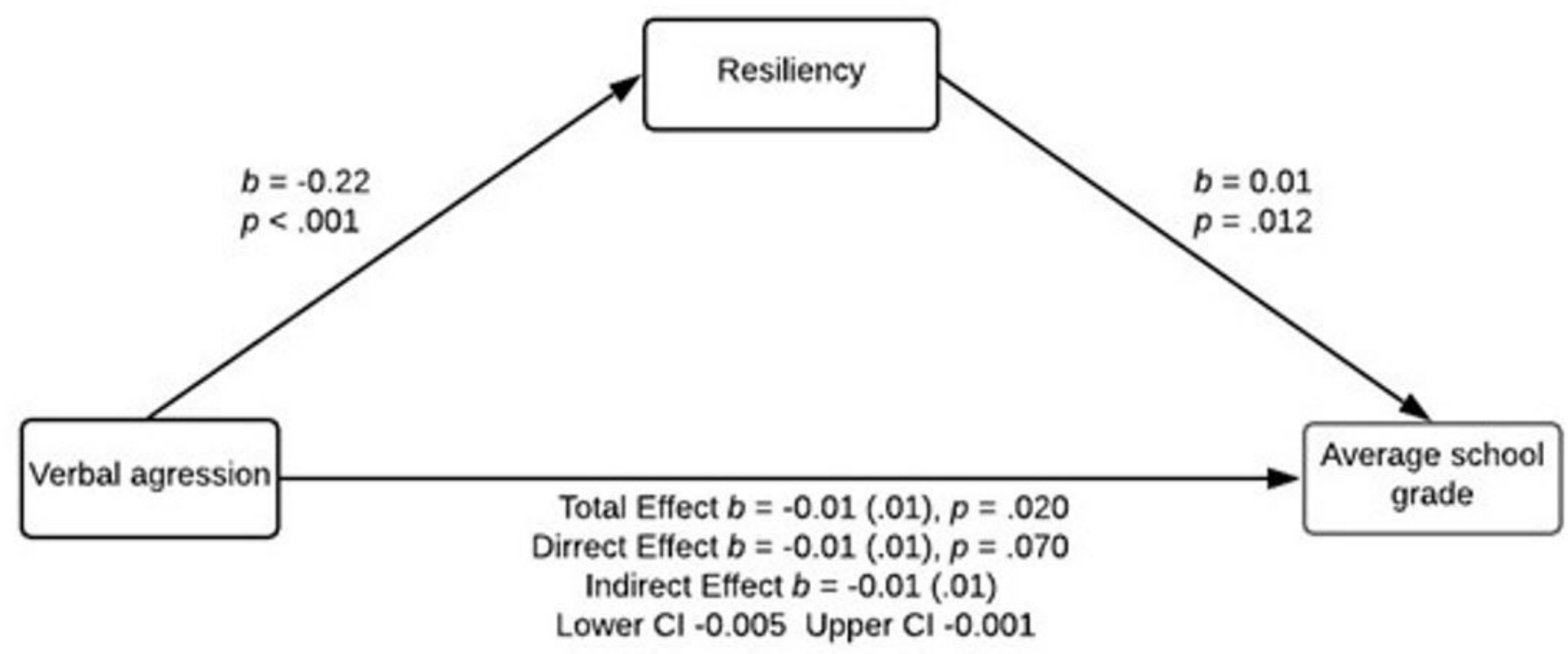

Figure 4

The relationship between verbal aggression and average school grade mediated by resiliency in the female PE group. Note. Standard errors are provided in parentheses. 


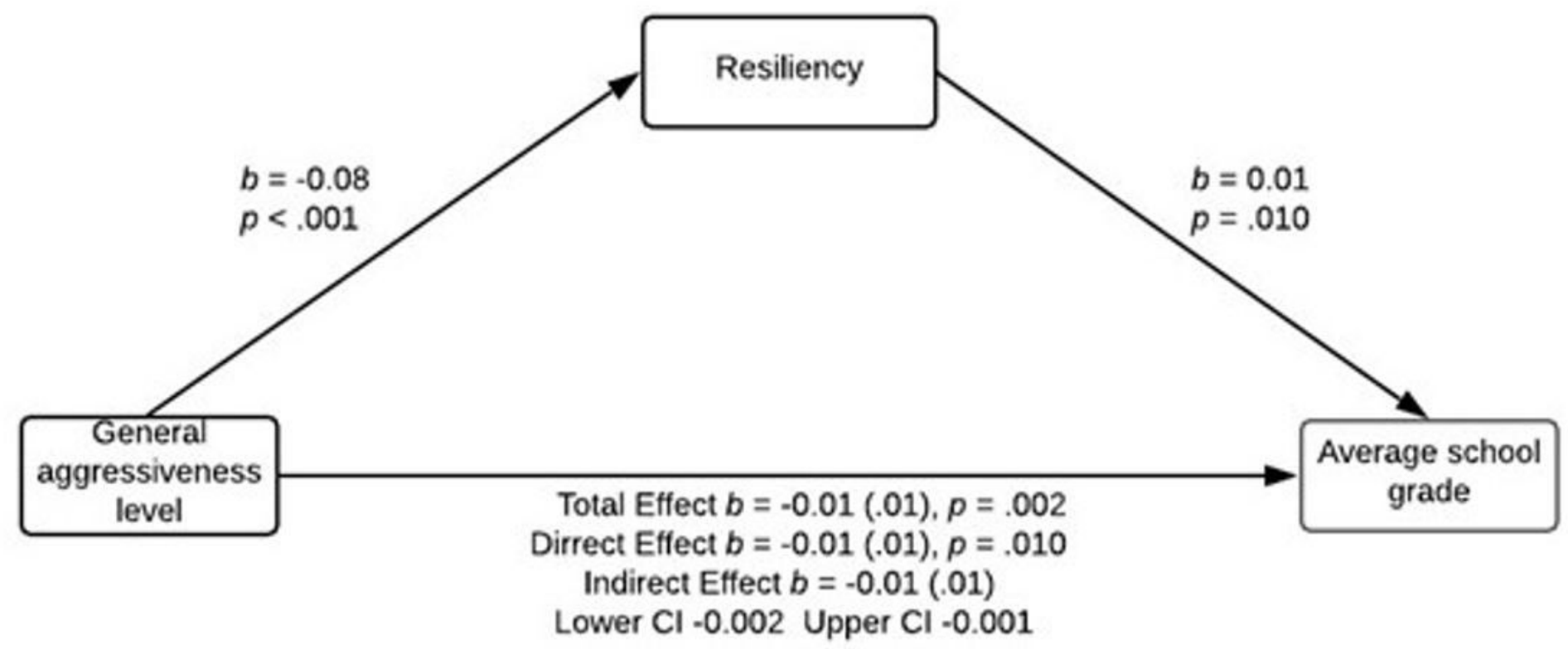

Figure 5

The relationship between general aggressiveness level and average school grade mediated by resiliency in the female PE group. Note. Standard errors are provided in parentheses.

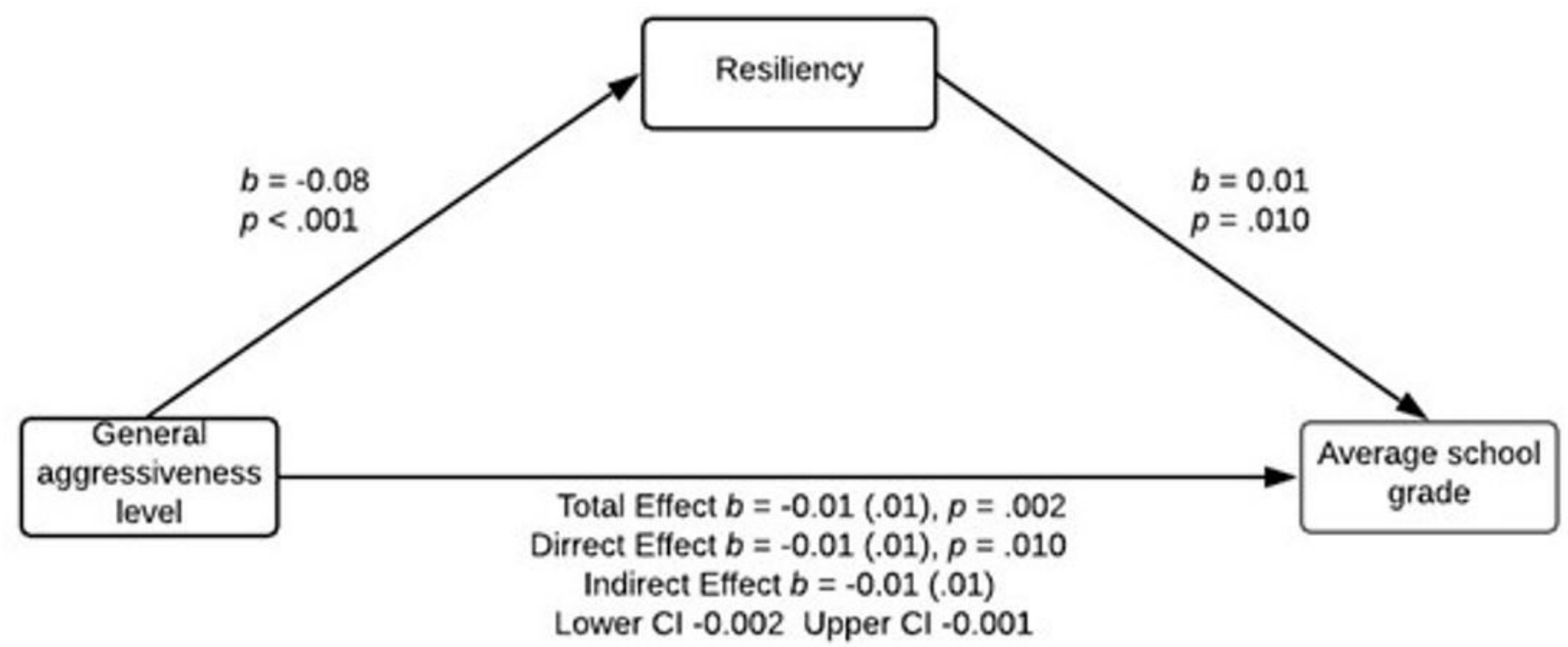

Figure 5

The relationship between general aggressiveness level and average school grade mediated by resiliency in the female PE group. Note. Standard errors are provided in parentheses. 